\title{
Water Content Control To Improve Space Charge Storage in a Cork Derivative
}

\author{
M. C. Lança ${ }^{1, a}$, I. Cunha ${ }^{1, b}$, J. P. Marques ${ }^{1, c}$, E. R. Neagu ${ }^{1,2, d}$, L.Gil $^{3, e}$, \\ C. J. Dias ${ }^{1, f}$ and J. N. Marat-Mendes ${ }^{1, g}$ \\ ${ }^{1}$ Cenimat//3N, Departamento de Ciência dos Materiais, Faculdade de Ciências e Tecnologia, \\ Universidade Nova de Lisboa, 2829-516 Caparica, Portugal \\ ${ }^{2}$ Department of Physics, Technical University of lasi, lasi 700050, Romania \\ ${ }^{3}$ Laboratório Nacional de Energia e Geologia (LNEG), Est. do Paço do Lumiar, 22, 1649-038 \\ Lisboa, Portugal

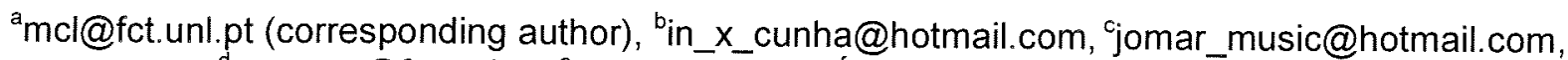

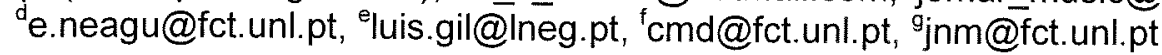

Keywords: cork; electrical properties; dielectric relaxation; space charge.

\begin{abstract}
The influence of humidity content on the electrical and dielectric properties of a composite made from recycled TetraPak $(B)$ containers and granulated cork was studied. The material components have been dried before preparation and after the composite was conditioned by keeping the samples in a dry environment (desiccator) or in an oven at high temperature $\left(70^{\circ} \mathrm{C}\right.$ in air). The differences observed in electrical properties (investigated by isothermal charge and discharge current measurement) and dielectric properties (measured using dielectric relaxation spectroscopy) show that the thermal treatment at high temperature is more efficient on removing water and slows down the re-absorption rate.
\end{abstract}

\section{Introduction}

A composite of recycled cork and used TetraPak ${ }^{\circledR}$ containers was developed at LNEG/Portugal and possible applications are still under study [1]. The structure of cork (a cellular material with closed cells in the microscale filled with gas) may suggest that it is possible to make the composite able to store charge and to have a piezoelectric behaviour [2,3]. This requires studying and understanding the electrical and dielectric properties of this material. Previous studies [4-6] have shown that the properties are strongly dependent on water content (typical water amount in natural cork is around $4 \% \mathrm{wt}$, and there is also to take into account the hygroscopic paper present in TetraPak( $)$ ). Therefore the latest studies seek to control the amount of humidity and understand its influence on the relevant properties of the material. A first change was made in the composition formulation by adding a hydrophobic material, paraffin, in order to reduce the water amount in the composite [6].

Some studies of electrical and dielectric properties have been previously published for natural cork, commercial cork agglomerate and for the cork/TetraPak $₫$ composite $[4,5]$. But only recently the cork/TetraPak $® /$ Paraffin composite was produced and started to be studied [6]. These studies indicate a strong influence of water content on the value of the electrical conductivity of cork of several orders of magnitude [4].

Originally the material was produced by grinding and hot pressing the two components. However in order to reduce the amount of water in the final product, as stated before, a wax was added and, in addition, the powders were dried previous to pressing [6].

In this work a composite of cork (48\% wt.)/TetraPak® $(48 \%$ wt.)/Commercial paraffin (4\% wt.) was produced. After pressing the samples were stored for a long period of time, either in a dry atmosphere at room temperature (desiccator) or in air at $70^{\circ} \mathrm{C}$ until measurements were made.

The composite samples were analyzed using isothermal charging and discharging currents (ICC/IDC) measurements and dielectric relaxation spectroscopy (DRS). For the isothermal measurements the value of the applied DC electric field was 2 to $10 \mathrm{~V} / \mathrm{mm}$ and the ICC/IDC 